\title{
Identification of glycosaminoglycan binding regions in the Plasmodium falciparum encoded placental sequestration ligand, VAR2CSA
}

\author{
Mafalda Resende ${ }^{1}$, Morten A Nielsen ${ }^{1}$, Madeleine Dahlbäck ${ }^{1}$, Sisse B Ditlev ${ }^{1}$, \\ Pernille Andersen ${ }^{2}$, Adam F Sander ${ }^{1}$, Nicaise T Ndam ${ }^{3}$, Thor G Theander ${ }^{1}$ and \\ Ali Salanti*1
}

Address: ${ }^{1}$ Centre for Medical Parasitology at Institute of International Health Immunology and Microbiology, University of Copenhagen and Department of Clinical Microbiology, Copenhagen University Hospital (Rigshospitalet), Copenhagen, Denmark, ${ }^{2}$ Center for Biological Sequence Analysis, BioCentrum-DTU, Copenhagen, Denmark and ${ }^{3}$ Laboratoire de Parasitologie, Institut de Recherche pour le Développement, Université Paris Descartes, Paris, France

Email: Mafalda Resende - mafaldaresende@gmail.com; Morten A Nielsen - morten.nielsen@rh.regionh.dk; Madeleine Dahlbäck - dahlback@cmp.dk; Sisse B Ditlev - sditlev@cmp.dk; Pernille Andersen - pan@cbs.dtu.dk; Adam F Sander - sander@cmp.dk; Nicaise T Ndam - Nicaise.Ndam@ird.fr; Thor G Theander - theander@cmp.dk; Ali Salanti* - salanti@cmp.dk * Corresponding author

Published: 6 June 2008

Malaria Journal 2008, 7:104 doi:10.1186/1475-2875-7-104
Received: 26 February 2008

Accepted: 6 June 2008

This article is available from: http://www.malariajournal.com/content/7/1/104

(C) 2008 Resende et al; licensee BioMed Central Ltd.

This is an Open Access article distributed under the terms of the Creative Commons Attribution License (http://creativecommons.org/licenses/by/2.0), which permits unrestricted use, distribution, and reproduction in any medium, provided the original work is properly cited.

\begin{abstract}
Background: Pregnancy malaria is caused by Plasmodium falciparum-infected erythrocytes binding the placental receptor chondroitin sulfate $A$ (CSA). This results in accumulation of parasites in the placenta with severe clinical consequences for the mother and her unborn child. Women become resistant to placental malaria as antibodies are acquired which specifically target the surface of infected erythrocytes binding in the placenta. VAR2CSA is most likely the parasite-encoded protein which mediates binding to the placental receptor CSA. Several domains have been shown to bind CSA in vitro; and it is apparent that a VAR2CSA-based vaccine cannot accommodate all the CSA binding domains and serovariants. It is thus of high priority to define minimal ligand binding regions throughout the VAR2CSA molecule.

Methods: To define minimal CSA-binding regions/peptides of VAR2CSA, a phage display library based on the entire var2csa coding region was constructed. This library was screened on immobilized CSA and cells expressing CSA resulting in a limited number of CSA-binding phages. Antibodies against these peptides were affinity purified and tested for reactivity against CSAbinding infected erythrocytes.

Results: The most frequently identified phages expressed peptides residing in the parts of VAR2CSA previously defined as CSA binding. In addition, most of the binding regions mapped to surface-exposed parts of VAR2CSA. The binding of a DBL2X peptide to CSA was confirmed with a synthetic peptide. Antibodies against a CSA-binding DBL2X peptide reacted with the surface of infected erythrocytes indicating that this epitope is accessible for antibodies on native VAR2CSA on infected erythrocytes.

Conclusion: Short continuous regions of VAR2CSA with affinity for multiple types of CSA were defined. A number of these regions localize to CSA-binding domains and to surface-exposed regions within these domains and a synthetic peptide corresponding to a peptide sequence in DBL2 was shown to bind to CSA and not to CSC. It is likely that some of these epitopes are involved in native parasite CSA adhesion. However, antibodies directed against single epitopes did not inhibit parasite adhesion. This study supports phage display as a technique to identify CSA-binding regions of large proteins such as VAR2CSA.
\end{abstract}




\section{Background}

PAM (Pregnancy Associated Malaria) is a major health problem in malaria-endemic areas and on a world basis it affects millions of pregnant women and their offspring. The presence of parasites in the placenta of pregnant women can have serious consequences for both mother and child including: maternal anaemia, premature delivery, low birth weight and increased infant mortality [1]. In malaria endemic areas, children acquire clinical immunity after multiple infections, and adults are in general protected against malaria. Women who have acquired immunity against malaria during childhood become susceptible to malaria during pregnancy due to novel parasite phenotypes expressing unique antigens not encountered during childhood infections [2,3]. In areas of high parasite transmission PAM mainly affects primigravidae since immunity is acquired as a function of gravidity [1]. Protective antibodies target proteins expressed on the surface of infected erythrocytes (IE), which mediate binding to syncytiotrophoblasts. By this process, the parasite is not filtered through the spleen and thus avoids exposure to effector mechanisms, which clear erythrocytes infected with late blood stage parasite from circulation [4]. The best characterized surface protein is the Plasmodium falciparum erythrocyte membrane protein 1 (PfEMP1) $[5,6]$, which is encoded by the polymorphic var gene family containing 50-60 copies per parasite genome [7]. The PfEMP1 family constitutes high-molecular proteins of 200-400 kDa, which are highly polymorphic. Different PfEMP1 molecules have different receptor specificities, therefore switching between expression of various var genes in a mutually exclusive manner allows the parasite to modify its adhesion properties (reviewed in [8]). PfEMP1 proteins include three to seven Duffy-bindinglike (DBL) domains, which belong to a parasite adhesiondomain super-family present in erythrocyte invasion ligands called: erythrocyte-binding ligands (EBL). Antibodies against PfEMP1 can interfere with parasite binding and the successive acquisition of a broad range of PfEMP1 antibodies is important for the acquisition of immunity during childhood [9-13]. Several molecules such as ICAM-1 [14], VCAM-1 [15], thrombospondin [16], CD36 [17], and chondroitin sulfate A (CSA) [18,19] have been identified as host receptors for PfEMP1. In the placenta IE exclusively bind to the glycosaminoglycan CSA $[19,20]$. The parasite protein mediating IE adhesion to CSA in the placenta is a distinct member of the PfEMP1 protein family, named VAR2CSA [21]. High levels of anti-VAR2CSA antibodies are correlated with favourable birth outcome and they are acquired as a function of parity [22]. Disruption of the var2csa gene causes the loss of the IE's ability to bind CSA [23]. VAR2CSA is a large IE surface-expressed antigen consisting of six DBL domains with a total estimated molecular mass of $350 \mathrm{kDa}$. The ultimate aim of PAM vaccine development is to define a VAR2CSA con- struct capable of eliciting antibodies that inhibit binding of IEs to CSA. However, several of the VAR2CSA domains have in vitro affinity to CSA [24-26] and this complicates vaccine design. It is thus of high priority to define the minimal epitopes within each domain and inter-domains that have affinity to CSA.

Phage display is a strong and widely used tool for mapping protein ligand interactions and has in several studies been used to define adhesive parts of proteins present on the surface of different organisms causing infectious diseases (reviewed in [27]). Phage display has also been extensively used in malaria research. For vaccine development Casey and others [28], used phage display to isolate a phage-derived peptide that mimic an important epitope of AMA-1 and had the ability to induce functionally protective antibodies. Lanzillotti and others [29], used a phage display library to search for $P$. falciparum encoded motifs involved in erythrocyte invasion, and identified regions in EBA-175 and Ebl-1 like proteins binding to receptors on the human erythrocyte. EBA and Ebl belong to the same super family of Duffy-binding-like proteins as the DBL domains from VAR2CSA. We were thus encouraged to use this technique to search for CSA-binding motifs in VAR2CSA. In this study a phage display library was constructed based on the exon1 coding region of VAR2CSA. The library was biopanned on different sources of glycosaminoglycans (GAG) including: immobilized bovine CSA; immobilized proteoglycans purified from placentas - CSPG; CSA-expressing CHO cells, and BeWo cells derived from the human placental syncytiotrophoblasts. Five regions of VAR2CSA potentially involved in in vivo parasite sequestration were identified and are thus potential candidate components of a multivalent PAM vaccine.

\section{Methods \\ Cells}

The human choriocarcinoma cell line BeWo was purchased from the American Type Culture Collection [30]. The cells were maintained in Ham's F12 with L-glutamine culture medium (Lonza, Verviers, Belgium) supplemented with $10 \%$ FCS and $1 \%$ penicilin/streptavidin (Sigma-Aldrich, Ayshire, UK). Chinese Hamster ovary cells (CHO) were maintained in RPMI1640 (with Lglutamine and $25 \mathrm{mM}$ HEPES) (Lonza, Verviers, Belgium) suplemented with $10 \%$ FCS and 1\% penicilin/streptavidin.

\section{Construction of the var2csa phage display library}

The exon1 of var2csa was digested with DNase1 (SigmaAldrich, Brøndby, Denmark) and fragments of $100 \mathrm{bp}-$ $150 \mathrm{bp}$ were ligated into the T7select $415-1 \mathrm{~b}$ vector (Novagen Inc., Madison, USA) at EcoRI and HindIII sites. 
Phage packaging amplification and titration were performed according to the manufacturer's instructions [31].

\section{Selection of the GAG binding phages from T7var2csa library}

Different approaches to select for phages binding to CSA were used. Common to these approaches was the general procedure for selection of clones, which consisted in four rounds of biopanning, followed by infection of E. coli (BL21) with the selected phages. The bacteria were plated and individual plaques were amplified and sequenced.

(1) Phage selection on human choriocarcinoma cell line BeWo or CHO cell line:

BeWo/CHO cells were cultured in Nuclon ${ }^{\mathrm{TM}}$ delta surface (Nunc, Roskilde, Denmark) 6 well-plates until confluent. The plates were incubated for 15 minutes at $4^{\circ} \mathrm{C}$ before adding $1 \times 10^{9}$ plaque forming units (pfu) T7var2csa phages to the cells for 1 hour at $37^{\circ} \mathrm{C}$. The cells were then washed carefully four times in pre-warmed $1 \%$ Bovine Serum Albumin (BSA) in PBS for five minutes per wash. The bound phages were eluted in $1 \mathrm{ml}$ of $0.2 \mathrm{M}$ glycin $\mathrm{pH}$ 6 for 10 minutes. The eluted phages were amplified to ensure a titer of $10^{9} \mathrm{pfu}$ for input phages at the start of each successive round.

\section{(2) Phage selection on biotinylated CSA}

CSA (C9819 Sigma-Aldrich, Brøndby, Denmark) was biotinylated using EZ-Link Sulfo-NHS-LC-Biotinylation kit (Pierce, Bonn, Germany). $100 \mu \mathrm{l}$ of $50 \mu \mathrm{g} / \mathrm{ml}$ biotinylated CSA in PBS was added to pre-coated avidin plates (Nunc, Roskilde, Denmark) for 1 hour at room temperature and the wells were subsequently blocked with $200 \mu \mathrm{l}$ of $1 \%$ BSA in PBS for 1 hour. After washing the plates three times with PBS, $1 \times 10^{9}$ pfu of T7var 2 csa phages were added to the plate for 1 hour at $37^{\circ} \mathrm{C}$. The wells were then washed twice in round 1 , three times in round 2 , and five times in subsequent rounds with TBS $0.5 \%$ Tween-20 for 3 minutes. The phages were eluted in $100 \mu \mathrm{l}$ of $0.1 \mathrm{M}$ glycin $\mathrm{pH} 2.2$ for 10 minutes, neutralized immediately with
$6 \mu$ of $2 \mathrm{M}$ Tris base $\mathrm{pH} 8$ and added to fresh log-phase BL21 cells.

(3) Phage selection on human placenta derived chondroitin sulfate proteoglycans (CSPG) [32] or bovine CSA (Sigma). Proteoglycan ( $5 \mu \mathrm{g} / \mathrm{ml}$ in PBS) was coated to microtiter plates (Nunc, Roskilde, Denmark) overnight at $4^{\circ} \mathrm{C}$. The following steps were done as described for biotinylated CSA.

\section{PCR amplification of plaques}

A portion of top agarose of an individual plaque of interest was scrapped by a pipette tip, dispersed in a tube containing $100 \mu \mathrm{l}$ of $10 \mathrm{mM}$ EDTA, and heated at $65^{\circ} \mathrm{C}$ for 10 min. The plaques collected served as templates in a PCR reaction with primers for the $\mathrm{T} 7$ vector supplied by the manufacturer (Novagen, Madison, USA). $15 \mu \mathrm{l}$ of the reaction product was analysed on a $1 \%$ agarose gel. For sequencing, the PCR product was purified by Minielute purification kit (Qiagen) and $4 \mu$ l of pure PCR product was used in the sequencing reaction.

\section{Peptide synthesis}

Peptides were synthesized by Schafer-N, Århus, Denmark (P2c, P3, P4 and P5) or Sigma (P1, P2a, P2b) (Table 1). Peptides P1, P2a, b, c and P5 were synthesized with the addition of a terminal cystein for increased stability. P2 region is very long and difficult to synthetize and was therefore divided into two peptides P2a and P2c. P2b correspondes to the $\mathrm{P} 2 \mathrm{a}$ region and has the FCR3 isolate sequence. $\mathrm{PC}$ is a non-VAR2CSA peptide and it was used as a negative control (Table 1 ). Peptide identity and purity were analysed by MALDI-TOF mass spectrometry and high-performance liquid-chromatography (HPLC). The synthesized peptide sequences are shown in one-letter code (Table 1).

\section{Biotinylation of peptides}

All peptides were biotinylated using EZ-link Sulfo-NHSLC-Biotin (Pierce, Bonn, Germany) following the instructions for preferentially biotinylation of N-terminal $\alpha$ amino groups in peptides [33].

Table I: Amino acid sequence of the synthetic peptides identified by phage display

\begin{tabular}{|c|c|c|}
\hline Peptide ID & Protein ID & Sequence \\
\hline PI & 3D7 - DBLIX & ENQKNKYTELYQQNKC \\
\hline $\mathrm{P} 2 \mathrm{a}$ & 3D7 - DBL2X & GKKTQELKNIRTNSELLKEWIIAAFHEGKC \\
\hline $\mathrm{P} 2 \mathrm{~b}$ & FCR3 - DBL2X & EDVKDINFDTKEKFLAGCLIVSFHEGKC \\
\hline $\mathrm{P} 2 \mathrm{c}$ & 3D7 - DBL2X & LKPSHEKKNDDNGKKLCKAC \\
\hline P3 & 3D7 - DBL3X & IKKIIEKGTTKQNGKTVGSGAEN \\
\hline P4 & $3 \mathrm{D} 7-\mathrm{DBL} 4 \varepsilon$ & IKNKNDITNAKKELLETLQIVAERE \\
\hline P5 & $3 \mathrm{D} 7-\mathrm{DBL} 5 \varepsilon$ & ILKGAQSEGKFLGNYYNEDKDKEKALEAMC \\
\hline PC & P. falciparum Potassium pump & WRRDTYNMIWGFNKIPTYIYNMLLILLSTSYID \\
\hline
\end{tabular}




\section{GAG binding ELISA}

Flat-bottomed, 96 well plates (Falcon 351172) were coated for 2 hours at $37^{\circ} \mathrm{C}$ either with CSA (C9819 SigmaAldrich, Brøndby, Denmark) $50 \mu \mathrm{g} / \mathrm{ml}$ in PBS; CSC (shark cartilage, Seikagaku, Tokyo, Japan) $50 \mu \mathrm{g} / \mathrm{ml}$ in PBS; or only PBS (as a negative control). The plates were then blocked for 1 hour at $37^{\circ} \mathrm{C}$ with $1 \%$ BSA, $0.05 \%$ Tween 20, in PSM buffer (PBS, $2 \mathrm{mM} \mathrm{CaCl}_{2}, 2 \mathrm{mM} \mathrm{MgCl}_{2}, \mathrm{pH} 7$ ). After two times washing with $0.05 \%$ Tween 20 in PSM buffer, $50 \mu \mathrm{l}$ of a dilution series $(0.4-25 \mu \mathrm{g} / \mathrm{ml})$ of peptide in blocking buffer was added per well and incubated overnight at $4^{\circ} \mathrm{C}$. After three times washing, $50 \mu \mathrm{l}$ of a $1 /$ 2000 dilution of a streptavidin-conjugated horseradish peroxidase antibody (Dako, Glostrup, Denmark) in blocking buffer was added to each well and incubated at $37^{\circ} \mathrm{C}$ for one hour. The binding assay was finalized with three times washing and developing with $100 \mu \mathrm{l} /$ well of ophenylenediamine substract for 10 minutes. Plates were read at $490 \mathrm{~nm}$. The curves (Figure 3A) are typical of four independent experiments, and each absorbance value is the mean of two experiments. Figure 3B absorbance values are the result of one experiment.

\section{Affinity purification of peptide-specific rabbit antibodies} Affinity purification of antibodies was done according tomanufacturer's instructions. In brief, $0,5 \mathrm{mg}$ of peptide was dialyzed against $0.2 \mathrm{M} \mathrm{NaHCO}_{3}, 0.5 \mathrm{M} \mathrm{NaCl}(\mathrm{pH}$ 8.3), and applied to a NHS-activated HiTrap 1-ml column (GE Healthcare) that had been equilibrated with $3 \times 2 \mathrm{ml}$ $1 \mathrm{mM} \mathrm{HCl}$. After coupling, the column was washed with $0.5 \mathrm{M}$ ethanolamine, $0.5 \mathrm{M} \mathrm{NaCl}(\mathrm{pH} 8), 0.1 \mathrm{M}$ acetate, $0.5 \mathrm{M} \mathrm{NaCl}(\mathrm{pH} 4)$, and a final wash with PBS (pH 7.4). $3 \mathrm{ml}$ of rabbit antisera against the specific domain [34] was subsequently added to the column. After washing in $10 \mathrm{ml}$ PBS, affinity-bound antibodies were eluted by $\mathrm{CH}_{3} \mathrm{COONH}_{4}(\mathrm{pH} 3)$ and neutralized in $1 \mathrm{M}$ Tris $(\mathrm{pH}$ 7.5). The specificity of the purified antibodies was tested in ELISA against (1) the peptide used for affinity purification, and (2) other VAR2CSA peptides. The affinity-purified antibodies were only positive against the VAR2CSA peptides on which they had been affinity purified.

\section{Parasite culture and selection}

The NF54 laboratory strain of P. falciparum was used. Parasite culture was done as previously described [34]. The genotype of the parasite was regularly checked by GLURP and MSP2-specific primers in a single PCR step.

To create a VAR2CSA-expressing parasite population, the NF54 parasites were repeatedly panned on VAR2CSA-specific antibodies creating the NF54var2ssa parasite line. Briefly, late stage trophozoites were obtained by gelatin purification and washed twice in RPMI1640. The IE were then incubated for 0.5 hour at $37^{\circ} \mathrm{C}$ with VAR2CSADBL5 $\varepsilon$-specific rabbit antiserum and washed three times with medium to remove unbound antibodies. IE expressing VAR2CSA were isolated by the use of protein G-coupled magnetic beads (Dynal, Invitrogen) on a MACS magnet (Miltenyi Biotec). The suspension of IE and beads was washed three times and added to a culture flask with $4 \%$ hematocrit of uninfected erythrocytes in $5 \mathrm{ml}$ culture medium. After 24 hours, the beads were removed by magnetic separation. This was repeated until parasites specifically expressed VAR2CSA on the surface. Expression of the $\mathrm{VSA}_{\text {PAM }}$ phenotype was confirmed by specific binding of parasites to CSA in static binding assays, and exclusive recognition of the surface of the IE by antibodies from women exposed to P. falciparum during pregnancy.

\section{Flow cytometry and IFA}

Flow cytometry was used to test if the peptide-specific antibodies recognize the surface of CSA-binding IEs. Parasite cultures (NF54VAR2CSA) were enriched to contain $>75 \%$ erythrocytes infected by late trophozoite and schizont stage parasites by exposure to a strong magnetic field [35]. Aliquots $\left(2 \times 10^{5} \mathrm{IE}\right)$ were labeled by ethidium bromide (to allow exclusion of remaining uninfected erythrocytes). For IE surface staining with rabbit anti-peptide IgG, samples were sequentially exposed to $20 \mu \mathrm{l}$ sera followed by $1 \mu$ l biotinylated sheep-anti-rabbit IgG (The Binding Site, Birmingham, UK) and to $0.5 \mu \mathrm{l}$ streptavidin-FITC (BD Pharmingen, San Diego, US). All incubations were performed in a total volume of $100 \mu \mathrm{l}$ PBS with $2 \%$ FCS for 30 minutes. Samples were washed two times with $3 \mathrm{ml}$ PBS, 2\% FCS between each incubation. Data from a minimum of 5000 IE were acquired using a FC500 flow cytometer (Beckman Coulter, Ramcon, Denmark). For each sample, the mean fluorescence index (MFI) was recorded as a measure of VSA-specific IgG reactivity. Each assay was repeated three times on separate days with similar results. A batch of uninfected erythrocytes was analysed to exclude IgG binding to erythrocyte antigens.

The wet immuno-fluorescent preparations were performed following the staining procedure described for the flow cytometry assays with a few modifications: DNA was labelled with $10 \mathrm{ng} / \mathrm{ml}$ DAPI and in the final staining step $0.5 \mu$ l Streptavidin-Alexa ${ }^{\circledR} 488$ was used instead of FITC (Invitrogen, Paisley, UK). Images were taken using a TE 2000-E Nikon Eclipse confocal microscope, using a 100× Apoplan oil immersion objective. Images were captured using the EZ-C1 Gold imaging system (version 3.30). Images of each parasite preparation stained with VAR2CSA-specific antibodies, peptide-specific antibodies or control antibodies were captured without adjusting pixel dwell time, laser-power nor photomultiplier gain. 


\section{Results \\ Multiple linear VAR2CSA regions have affinity for proteoglycans}

The exon 1 of var2csa has 9171 bp and was PCR amplified and cloned into the T7select $415-1 \mathrm{~b}$ phage vector. The plasmid was propagated and the insert containing the whole var2csa exon 1 was cut out and digested with DNase 1 to generate $200 \mathrm{bp}$ fragments. The var2csa fragments were used to create a T7 Phage display library as described in the material and methods section. This vector is described to display 415 copies of peptides on the surface of the T7 capsid [31].

To ensure that all parts of VAR2CSA exon 1 were present in this constructed library a number of clones were sequenced before biopanning. No sequences were overrepresented and sequences belonging to all six DBL domains were present in the library (Figure 1A, black). The var2csa phage display library was biopanned four rounds on: CHO cells (two independent assays); human placental choriocarcinoma cell line BeWo (four independent assays); bovine CSA (two independent assays); biotinylated CSA (two independent assays) and chondroitin sulfate proteoglycans of human placenta (CSPG) (two independent assays). Control biopannings were done on ELISA plates coated with BSA (Figure 1A, Blocking Bf, blue). From each assay 15 clones were sequenced. Figure 1 shows the frequency by which different phages expressing particular VAR2CSA regions were identified after the different types of biopanning. Biopanning on CSA resulted in enrichment of a single region (20\% of all phages) corresponding to a peptide sequence in DBL3 (Figure 1A, green). CSA coated directly on ELISA plates might not be very efficient; therefore the biopanning was subsequently repeated using biotinylated CSA (bCSA). This resulted in enrichment of phages representing sequences present in DBL1, DBL2 and DBL4 (Figure 1A, red). In addition, biopanning on human placental CSPG resulted in enrichment of phages representing DBL4 and DBL5 sequences (Figure 1A, yellow). However, the DBL4 sequence was also present in $18 \%$ of the control BSA biopannings (Figure 1A, blue). To further identify proteoglycan-binding regions, the VAR2CSA phage display library was biopanned on BeWo and CHO cells expressing CSPG and CSA, respectively (Figure 1B). Enrichment of phages expressing peptides from DBL2, DBL3, DBL4 and DBL5 was seen. Again the DBL4 sequence was also detected in the phages from the control biopanning. DBL2 and DBL3 phages binding to the GAG expressing cells contained VAR2CSA sequences that overlapped with the sequences identified by the CSA biopanning. The DBL5 sequence overlapped with the clone identified by CSPG biopanning. In summary, five relatively short stretches of VAR2CSA appeared to bind soluble GAGs as well as GAGs expressed on cells. No none-DBL regions (i.e. NTS, ID1 or ID2) were identified as GAG binding.

Mapping the phage display selected regions on models of VAR2CSA DBL domains and comparing with the previous described surface-expressed epitopes

Structural models of VAR2CSA 3D7 DBL domains have previously been produced using the solved DBL structures in EBA-175 and Pko-DBL as templates [36]. As part of previous work we identified regions on native VAR2CSA, which were accessible to antibodies $[26,36]$. In the current study, the CSA-binding regions defined by the phage display screening were mapped onto the models and compared to the previous findings (Figure 2). Interestingly, in DBL2, DBL3 and DBL5 there was a high degree of overlap between the CSA-binding regions and the surface-exposed regions (Figure 2, green). Peptides residing in DBL1 and DBL4 did not map to the predicted surface exposed regions. All mapped regions, except the DBL1 region, mapped to the S2 subdomain of the DBL domains. The CSA-binding regions mapped in DBL2 and DBL5 are in close vicinity to the chemokine-binding site region of Pka-DBL Duffy [37].

\section{Synthetic peptides representing PI-P5}

Seven peptides, corresponding to VAR2CSA regions P1-P5 (Figure 1 and Table 1), were synthetized and biotinylated to evaluate their ability to bind CSA in an ELISA assay. For the ELISA based CSA-binding assay: plates were coated with CSA and binding was measured using a streptavidinconjugated peroxidase-antibody. In order to determine the background binding and detect the true signal, half of the plate was not coated with CSA but all the subsequently steps were performed equally in the whole plate. Using this assay P2b (DBL2) showed specific binding to CSA compared to the background and additionally did not bind to CSC (Figure 3, red curves). A non-VAR2CSA control peptide (Table 1, PC) was used (Figure 3, blue curves) and didn't show binding to any of the GAGs.

\section{Antibodies specific to the $D B L 2 X$ peptide react with native VAR2CSA on the surface of infected erythrocytes}

Sera from rabbits immunized with recombinant VAR2CSA DBL domains [34] were tested for reactivity against the six peptides. Rabbits immunized with recombinant whole domain DBL1 and DBL4 did not react with the peptides from these domains (P1 and P4). Rabbits immunized with recombinant whole domain DBL2, DBL3 and DBL5 reacted with P2, P3, and P5, respectively. Peptide-specific antibody reagents were then produced by affinity purifying rabbit antibodies on the peptides. The affinity-purified antibodies were tested in flow cytometry for reactivity with native VAR2CSA expressed on erythrocytes infected with the NF54 parasite strain (Figure 4A). Anti-P2c peptide specific antibodies stained the surface of 


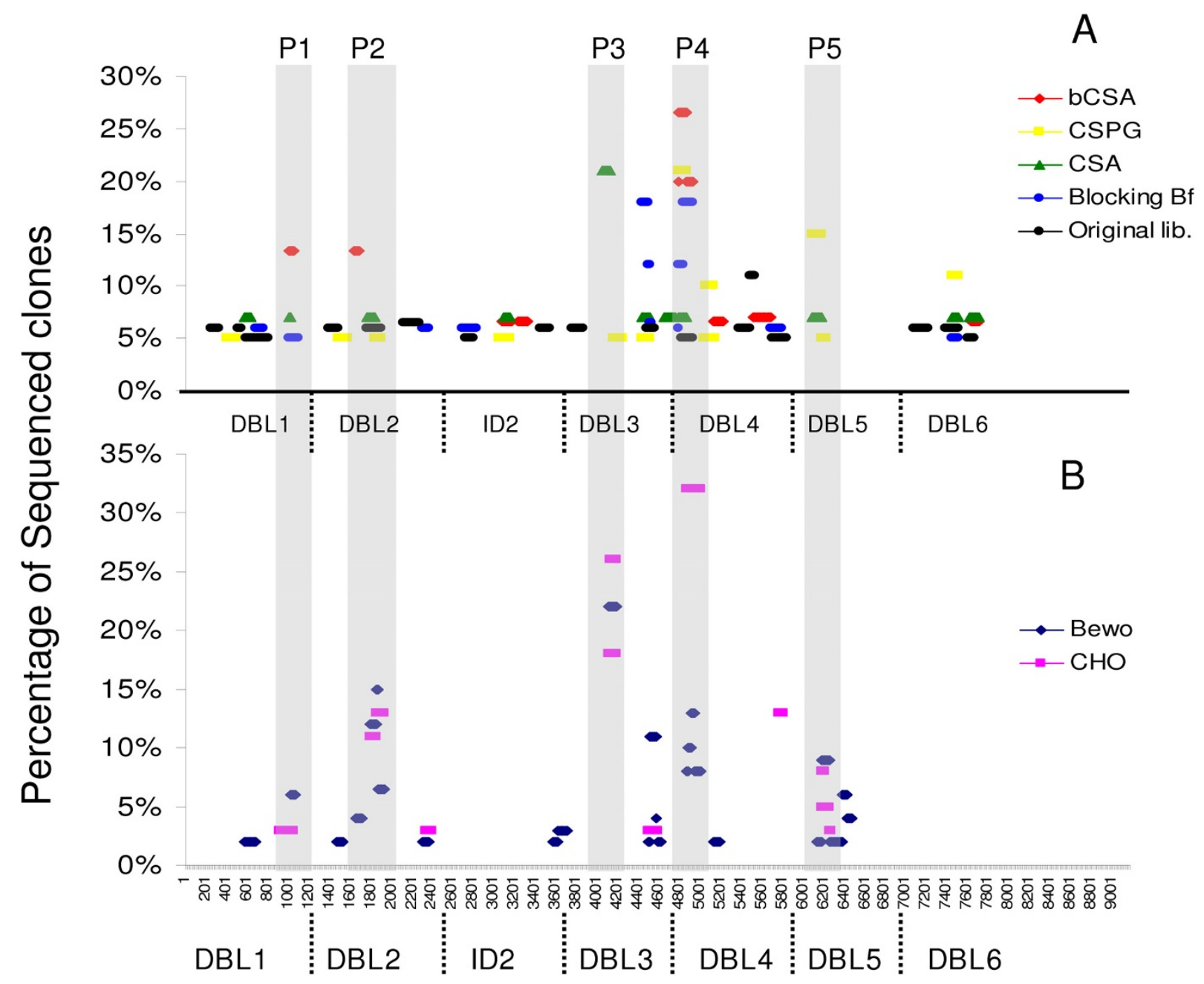

Figure I

Frequency of identifed phages sorted according to the identity of the VAR2CSA region and the method of biopanning. The var2csa phage display library was biopanned four rounds on each of the following: biotinylated CSA (A, red); Chondroitin sulfate proteoglycans of human placenta (CSPG) (A, yellow); bovine CSA (A, green); CHO cells expressing CSA on the surface $(B$, pink) and human placental choriocarcinoma cell line $B e W o(B, b l u e)$. Control biopannings were done on ELISA plates coated with BSA (A, blue) and the original library was sequenced prior to selection to confirm the presence of sequences belonging to all domains (A, black). For each assay 15 CSA-binding clones were sequenced. Each coloured bar indicates the VAR2CSA sequence expressed by the selected phage on the $x$-axes and the frequency by which the sequence was detected by sequencing on the $y$-axes. The length of the coloured bar indicates the length of the VAR2CSA sequence in the selected phage. The VAR2CSA regions most often expressed by the CSA-binding phages are shaded in grey (PI-P5).

the infected CSA-binding erythrocytes. In addition, the reactivity was observed by wet IFA (Figure 4B). The surface staining determined by IFA showed a dotted pattern typical of PfEMP1 staining. We were unable to detect binding with P2a, P2b, P3 and P5 specific antibodies.

\section{Discussion}

Malaria parasites causing PAM have been shown to bind to glycosaminoglycans in the intevillous space of the placenta. These parasites also bind specifically to bovine CSA [18], CSPG [38] as well as BeWo [39] and CHO cells hav- ing CSPG on the surface [18]. The binding between the parasite and the placental CSPG is most likely mediated through the parasite expressed protein, VAR2CSA. VAR2CSA is a large multidomain protein and for vaccine development it is important to define which regions of VAR2CSA are responsible for the interaction with CSPG. In the present study a var2csa phage display library was biopanned on five different CSA containing targets (bovine CSA, bovine bCSA, human placental CSPG, BeWo and CHO cells) in 12 independent experiments. Five regions of VAR2CSA repeatedly showed affinity for 

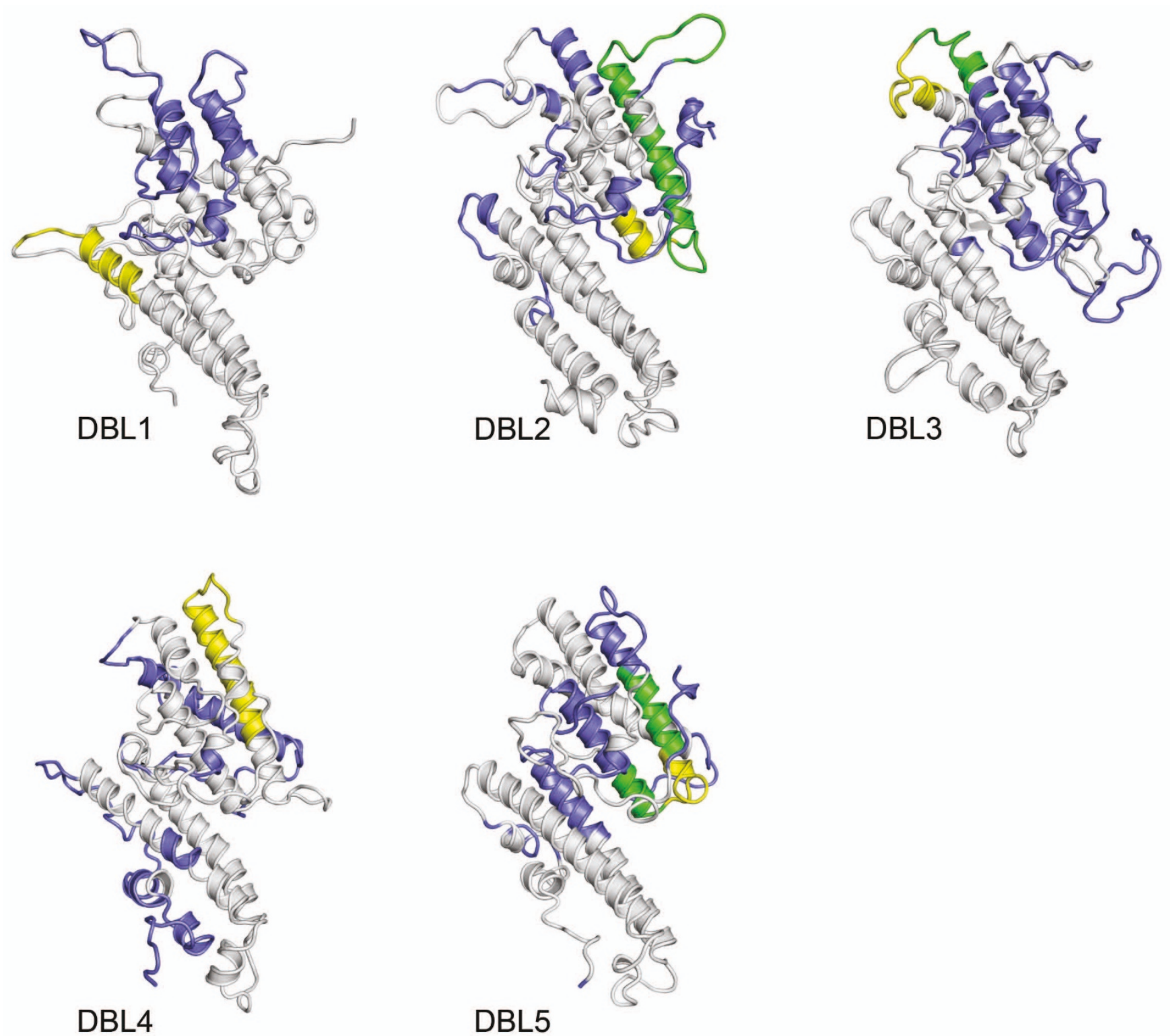

Figure 2

Structural models of VAR2CSA DBL domains showing surface-exposed regions and GAG binding regions. The surface-exposed epitopes previously determined by depleting female IgG plasma on parasites expressing VAR2CSA are shown in blue. The GAG binding regions identified by phage display assays are shown in yellow. The overlap of surface-exposed regions and GAG binding regions is shown in green.

the different CSA preparations. The CSA-binding peptides identified with the phage display approach were based on the linear sequence of VAR2CSA. However, the CSA binding region might be conformational and involve peptides from several domains. It is preferable that results obtained by phage display assays are confirmed by showing that peptides corresponding to the identified regions also possess binding capacity. The var2csa phage display library used in this study was constructed from DNA fragments of
100-150 bp, and the corresponding peptides are thus 3475 aa. These long peptides were difficult to synthetize and were unstable in solution and we thus had to divide some of the phage regions into several synthetic peptides. Furthermore, the structure of peptides in solution might be very different from peptides bound to a phage. These factors could explain why only one out of seven synthetic peptides could have its binding to CSA confirmed. 

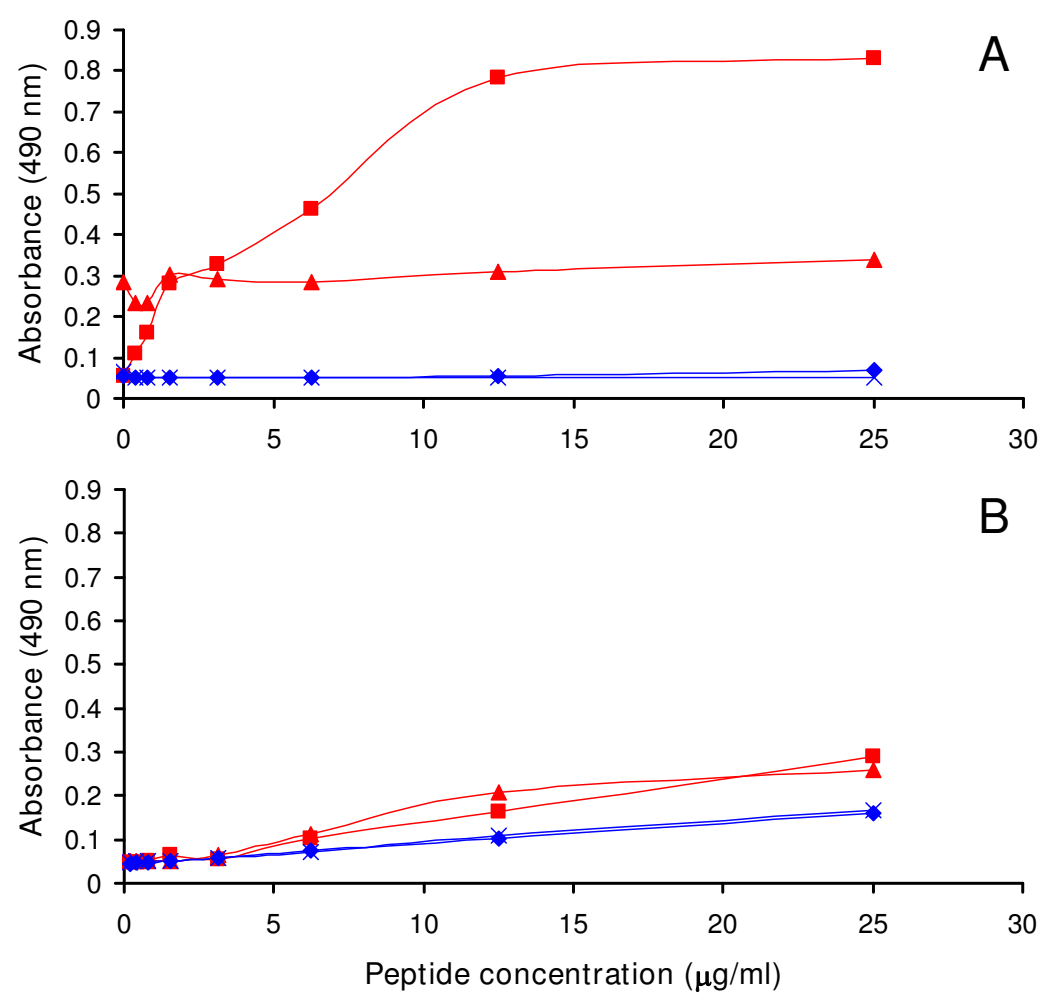

\section{Figure 3}

A DBL2 peptide binds to CSA and not to CSC. (A) Peptide binding assay to CSA: P2b (red) binds to CSA ( $\square$ ) in a peptide concentration-specific manner and not to the plate $(\mathbf{A})$. The control peptide (blue) does not bind to neither the plate $(x)$ nor CSA $(\bullet)$. (B) Peptide binding assay to CSC: P2b (red) does not bind to either CSC $(\boldsymbol{\square})$ or to the plate $(\mathbf{A})$. The control peptide (blue) does not bind to neither the plate $(\times)$ nor CSC $(\diamond)$.

DBL2, DBL3 and DBL5 domains of VAR2CSA have previously been shown to bind to CSA [24-26] and the surfaceexposed regions within these domains have been mapped $[26,36]$. Three of the five peptides are located on surfaceexposed parts of the previously described CSA-binding domains and two of these peptides map to regions on the DBL domains, which are in close proximity to the ligandbinding region of Pk-alfa-DBL [37]. These findings show an agreement between two independent approaches, which strengthens the present results. No CSA-binding epitopes were found in the highly polymorphic DBL6 domain, which previously has been shown to bind CSA indicating the presence of conformational CSA binding regions in this domain [25].

Region P2 was very long and had to be divided into two peptides for synthesis. The first part of the region showed specific CSA binding (P2b, Figure 3 ) and the second part of the region $(\mathrm{P} 2 \mathrm{C})$ using peptide affinity purified antibodies in IFA, confirmed that the CS- binding peptide region present in DBL2 was in fact surface-exposed in native VAR2CSA expressed on IE (Figure 4).

The affinity-purified antibodies did not inhibit parasite binding to CSA (data not shown), but this is not surprising as multiple epitopes/domains of VAR2CSA are suggested to be independently involved in CSA binding [2426]. However, it is possible that all domains of VAR2CSA contribute to a common CSA binding groove, either in a monomeric form or a di-polymeric form, such a glycan binding groove has been shown to be present in a reversehand shake dimer of EBA-175 [40]. Individual peptides and domains may have low affinity for binding to CSA, whereas high affinity is only achieved by the assembly of the entire binding site. Chrystallography and structure elucidation of an entire VAR2CSA molecule is not technical feasible with current technology, therefore a complex multi-domain CSA-binding site is difficult to identify. Current methods of identifying the CSA-binding regions of VAR2CSA primarily employ the ability of peptide-specific antibody reagents to inhibit parasite adhesion. If 

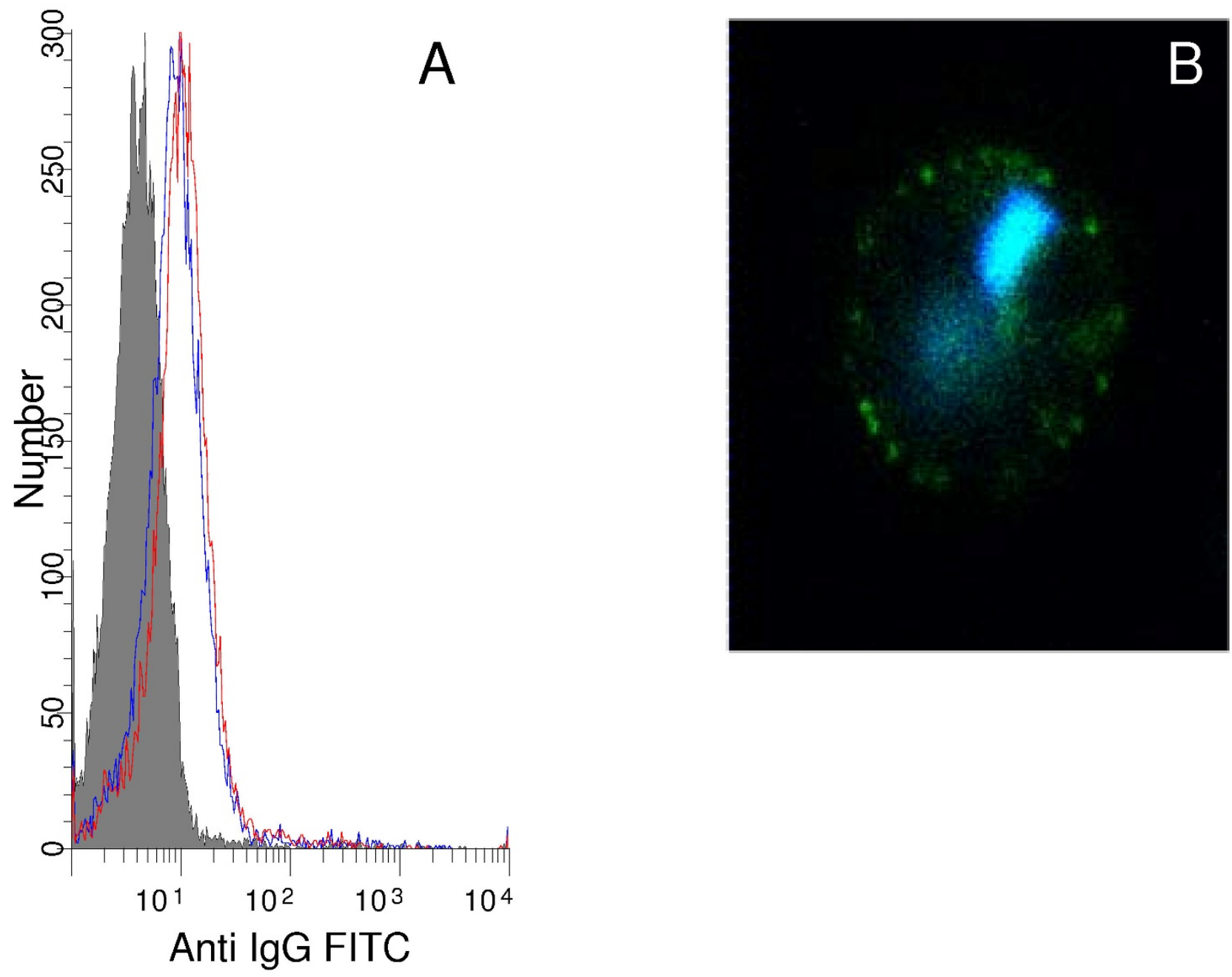

\section{Figure 4}

Anti-P2 antibodies react with native VAR2CSA expressed on the surface of infected erythrocytes. The histogram (A) shows staining of red blood cells infected with late stages of NF54var2csa. The IE reacted with rabbit affinity purified antibodies against P2c peptide (red) and DBL5 (blue). The rabbit prebleed is shown in solid grey. The picture (B) shows an IFA image of IE double stained with anti-P2c antibodies (green) and DNA (DAPI) staining (blue).

multiple sites are involved in adhesion, screening with single specificity antibodies might not suffice to identify a vaccine construct. By combining the knowledge from: recombinant DBL binding assays; parasite anti-adhesion assays using domain-specific antibodies; epitope mapping approaches and phage display approaches, we might be able to construct a chimeric vaccine, encompassing different CSA binding regions and important antibody epitopes. The phage display approach described here is the first study that attempts to find smaller CSA binding regions within the DBL domains of the vaccine candidate VAR2CSA.

\section{Conclusion}

Phage display was used to identify GAG binding linear regions of VAR2CSA. Five regions located in five different domains were found to have affinity for both immobilized CSA and CSA expressed on the surface of cells. The most frequently observed GAG binding phages mapped to DBL2, 3, 4 and DBL5, and except DBL4 all these domains have been shown to bind CSA in vitro. These results are supported by data published by Andersen and others [36], demonstrating that the phage display defined CSA-binding regions in DBL2, 3, 5 all locate to areas of VAR2CSA that appear to be exposed on the native molecule. The DBL2 CSA binding peptide showed specific binding to CSA and affinity-purified antibodies against 
the same phage display identified region reacted with the surface of infected erythrocytes. This work is the first step in defining small regions of VAR2CSA, which can be used in an adhesion blocking sub-unit vaccine protecting pregnant women against PAM.

\section{Abbreviations}

aa: amino acid; bp: base pair; BSA: bovine serum albumin; CSA: chondroitin sulfate A; DARC: Duffy Antigen Receptor for Chemokines; DBL: Duffy-binding-like; EBA: Erythrocyte Binding Antigen; Ebl: Erythrocyte binding ligand; ELISA: Enzyme-Linked Immunosorbent Assay; FCS: Fetal calf serum; ID1: Inter-Domain region 1 of PfMP1; IFA: Immunofluorescence assay; IgG: immunoglobulin gamma; LBW: low birth weight; NTS: N-terminal segment of PfMP1; PAM: pregnancy-associated malaria; PfEMP1: Plasmodium falciparum Erythrocyte Membrane Protein 1.

\section{Authors' contributions}

MR, MAN, MD and SD performed the experiments, PHA plotted GAG binding regions onto the VAR2CSA models, NTN purified the human CSPG used for this study, MR, MAN, NTN, AFS, MD, TGT, and AS were responsible for the study design and the interpretation of data. All authors contributed to writing of the manuscript and approved the final version.

\section{Acknowledgements}

MR is supported by a PhD scholarship from Copenhagen University (KU) and the Graduate School of International Health. MD and AS were supported by post doctoral grants from the Danish Medical Research Council (SSVF). MAN is supported by a post doctoral grant from Hovedstadens Sygehusfaellesskab. NTN was supported by a post doctoral grant from "Fondation pour la Recherche Médicale" (FRM). The study received financial support from Bill and Melinda Gates Foundation and from European Malaria Vaccine Initiative.

\section{References}

I. Brabin BJ: An analysis of malaria in pregnancy in Africa. Bull World Health Organ 1983, 61:1005-1016.

2. Fried M, Nosten F, Brockman A, Brabin BJ, Duffy PE: Maternal antibodies block malaria. Nature 1998, 395:85 I-852.

3. Ricke CH, Staalsoe T, Koram K, Akanmori BD, Riley EM, Theander TG, Hviid L: Plasma antibodies from malaria-exposed pregnant women recognize variant surface antigens on Plasmodium falciparum-infected erythrocytes in a parity-dependent manner and block parasite adhesion to chondroitin sulfate A. JImmunol 2000, I65:3309-33I6.

4. David PH, Hommel M, Miller LH, Udeinya IJ, Oligino LD: Parasite sequestration in Plasmodium falciparum malaria: spleen and antibody modulation of cytoadherence of infected erythrocytes. Proc Natl Acad Sci USA 1983, 80:5075-5079.

5. Smith JD, Chitnis CE, Craig AG, Roberts DJ, Hudson-Taylor DE, Peterson DS, Pinches R, Newbold Cl, Miller LH: Switches in expression of Plasmodium falciparum var genes correlate with changes in antigenic and cytoadherent phenotypes of infected erythrocytes. Cell 1995, 82:10I-IIO.

6. Su X, Heatwole VM, Wertheimer SP, Guinet F, Herrfeldt JA, Peterson DS, Ravetch JA, Wellems TE: The large diverse gene family var encodes proteins involved in cytoadherence and antigenic variation of Plasmodium falciparum-infected erythrocytes. Cell 1995, 82:89-100.
7. Gardner MJ, Hall N, Fung E, White O, Berriman M, Hyman RW, Carlton JM, Pain A, Nelson KE, Bowman S, Paulsen IT, James K, Eisen JA, Rutherford K, Salzberg SL, Craig A, Kyes S, Chan MS, Nene V, Shallom SJ, Suh B, Peterson J, Angiuoli S, Pertea M, Allen J, Selengut J, Haft $D$, Mather MW, Vaidya AB, Martin DM, Fairlamb AH, Fraunholz MJ, Roos DS, Ralph SA, McFadden GI, Cummings LM, Subramanian GM, Mungall C, Venter JC, Carucci DJ, Hoffman SL, Newbold C, Davis RW, Fraser CM, Barrell B: Genome sequence of the human malaria parasite Plasmodium falciparum. Nature 2002, 4|9:498-5II.

8. Wahlgren M, Fernandez V, Chen Q, Svärd S, Hagblom P: Waves of malarial var-iations. Cell 1999, 96:603-606.

9. Marsh K, Otoo L, Hayes RJ, Carson DC, Greenwood BM: Antibodies to blood stage antigens of Plasmodium falciparum in rural Gambians and their relation to protection against infection. Trans R Soc Trop Med Hyg 1989, 83:293-303.

10. Bull PC, Lowe BS, Kortok M, Molyneux CS, Newbold Cl, Marsh K: Parasite antigens on the infected red cell are targets for naturally acquired immunity to malaria. Nature Med 1998, 4:358-360.

II. Ofori MF, Dodoo D, Staalsoe T, Kurtzhals JAL, Koram K, Theander TG, Akanmori BD, Hviid L: Malaria-induced acquisition of antibodies to Plasmodium falciparum variant surface antigens. Infect Immun 2002, 70:2982-2988.

12. Duffy PE, Fried M: Antibodies that inhibit Plasmodium falciparum adhesion to chondroitin sulfate $A$ are associated with increased birth weight and the gestational age of Newborns. Infect Immun 2003, 71 :6620-6623.

13. Staalsoe T, Shulman CE, Bulmer JN, Kawuondo K, Marsh K, Hviid L: Variant surface antigen-specific IgG and protection against clinical consequences of pregnancy-associated Plasmodium falciparum malaria. Lancet 2004, 363:283-289.

14. Berendt AR, Simmons DL, Tansey J, Newbold Cl, Marsh K: Intercellular adhesion molecule-I is an endothelial cell adhesion receptor for Plasmodium falciparum. Nature 1989, 341:57-59.

15. Ockenhouse CF, Tegoshi T, Maeno Y, Benjamin C, Ho M, Kan KE, Thway Y, Win K, Aikawa M, Lobb RR: Human vascular endothelial cell adhesion receptors for Plasmodium falciparuminfected erythrocytes: roles for endothelial leukocyte adhesion molecule I and vascular cell adhesion molecule I. J Exp Med 1992, 176: II83-II89.

16. Roberts DD, Sherwood JA, Spitalnik SL, Panton LJ, Howard RJ, Dixit VM, Frazier WA, Miller LH, Ginsburg V: Thrombospondin binds falciparum malaria parasitized erythrocytes and may mediate cytoadherence. Nature 1985, 318:64-66.

17. Ockenhouse CF, Tandon NN, Magowan C, Jamieson GA, Chulay JD: Identification of a platelet membrane glycoprotein as a falciparum malaria sequestration receptor. Science 1989, 243: |469-|47|

18. Rogerson SJ, Chaiyaroj SC, Ng K, Reeder JC, Brown GV: Chondroitin sulfate $A$ is a cell surface receptor for Plasmodium falciparum-infected erythrocytes. J Exp Med 1995, 182:15-20.

19. Fried M, Duffy PE: Adherence of Plasmodium falciparum to chondroitin sulfate $\mathbf{A}$ in the human placenta. Science 1996, 272:1502-1504

20. Muthusamy A, Achur RN, Valiyaveettil M, Botti J], Taylor DW, Leke RF, Gowda DC: Chondroitin sulfate proteoglycan but not hyaluronic acid is the receptor for the adherence of Plasmodium falciparum-infected erythrocytes in human placenta, and infected red blood cell adherence up-regulates the receptor expression. Am J Pathol 2007, I 70: 1989-2000.

21. Salanti A, Staalsoe T, Lavstsen T, Jensen ATR, Sowa MPK, Arnot DE, Hviid L, Theander TG: Selective upregulation of a single distinctly structured var gene in chondroitin sulphate A-adhering Plasmodium falciparum involved in pregnancy-associated malaria. Mol Microbiol 2003, 49:179-191.

22. Salanti A, Dahlback M, Turner L, Nielsen MA, Barfod L, Magistrado P, Jensen AT, Lavstsen T, Ofori MF, Marsh K, Hviid L, Theander TG: Evidence for the involvement of VAR2CSA in pregnancyassociated malaria. J Exp Med 2004, 200: I 197- 203.

23. Viebig NK, Gamain B, Scheidig C, Lepolard C, Przyborski J, Lanzer M, Gysin J. Scherf A: A single member of the Plasmodium falciparum var multigene family determines cytoadhesion to the placental receptor chondroitin sulphate A. EMBO Rep 2005, 6:775-78I. 
24. Gamain B, Trimnell AR, Scheidig C, Scherf A, Miller LH, Smith JD: Identification of multiple chondroitin sulfate A (CSA)-binding domains in the var2CSA gene transcribed in CSA-binding parasites. J Infect Dis 2005, I9 I:1010-1013.

25. Avril M, Gamain B, Lépolard C, Viaud N, Scherf A, Gysin J: Characterization of anti-var2CSA-PfEMPI cytoadhesion inhibitory mouse monoclonal antibodies. Microbes Infect 2006, 8:2863-287I.

26. Dahlbäck M, Rask TS, Andersen PH, Nielsen MA, Ndam NT, Resende M, Turner L, Deloron P, Hviid L, Lund O, Pedersen AG, Theander TG, Salanti A: Epitope mapping and topographic analysis of VAR2CSA DBL3X involved in $P$. falciparum placental sequestration. PLoS Pathog 2006, 2:el 24.

27. Mullen LM, Nair SP, Ward JM, Rycroft AN, Henderson B: Phage display in the study of infectious diseases. Trends Microbiol 2006, | 4: 14 | - 147.

28. Casey JL, Coley AM, Anders RF, Murphy VJ, Humberstone KS, Thomas, Foley M: Antibodies to malaria peptide mimics inhibit Plasmodium falciparum invasion of erythrocytes. Infect Immun 2004, 72: I I 26-II34.

29. Lanzillotti R, Coetzer TL: Myosin-like sequences in the malaria parasite Plasmodium falciparum bind human erythrocyte membrane protein 4.I. Haematologica 2004, 89: I I68-II7I.

30. American Type Culture Collection [http://www.lgcpromo
[ chem-atcc.com/]

31. Novagen: T7Select System Manual TB I78. Novagen, Madison, WI 2002.

32. Badaut C, Faure G, Tuikue Ndam NG, Bertin G, Chaffotte A, Khattab A, Klinkert MQ, Deloron P, Bentley GA: Receptor-binding studies of the DBLgamma domain of Plasmodium falciparum erythrocyte membrane protein I from a placental isolate. Mol Biochem Parasitol 2007, I 5 I:89-99.

33. Sélo I, Négroni L, Créminon C, Grassi J, Wal JM: Preferential labeling of alpha-amino $\mathbf{N}$-terminal groups in peptides by biotin: application to the detection of specific anti-peptide antibodies by enzyme immunoassays. J Immunol Methods 1996, I99:|27-I38.

34. Nielsen MA, Resende M, Alifrangis M, Turner L, Hviid L, Theander TG, Salanti A: Plasmodium falciparum: VAR2CSA expressed during pregnancy-associated malaria is partially resistant to proteolytic cleavage by trypsin. Exp Parasitol 2007, I I 7: I-8.

35. Paul F, Roath S, Melville D, Warhurst DC, Osisanya JO: Separation of malaria-infected erythrocytes from whole blood: use of a selective high-gradient magnetic separation technique. Lancet 1981, 2:70-7I.

36. Andersen $P$, Nielsen MA, Resende M, Rask TS, Dahlbäck M, Theander $T$, Lund $O$, Salanti A: Structural insight into epitopes in the pregnancy-associated malaria protein VAR2CSA. PLoS Pathog 2008, 4:e42.

37. Singh SK, Hora R, Belrhali H, Chitnis CE, Sharma A: Structural basis for Duffy recognition by the malaria parasite Duffy-bindinglike domain. Nature 2006, 439:74I-744.

38. Achur RN, Valiyaveettil M, Alkhalil A, Ockenhouse CF, Gowda DC: Characterization of proteoglycans of human placenta and identification of unique chondroitin sulfate proteoglycans of the intervillous spaces that mediate the adherence of Plasmodium falciparum-infected erythrocytes to the placenta. J Biol Chem 2000, 275:40344-40356.

39. Haase RN, Megnekou R, Lundquist M, Ofori MF, Hviid L, Staalsoe T: Plasmodium falciparum parasites expressing pregnancy-specific variant surface antigens adhere strongly to the choriocarcinoma cell line BeWo. Infect Immun 2006, 74:3035-3038.

40. Tolia NH, Enemark EJ, Sim BK, Joshua-Tor L: Structural basis for the EBA-I75 erythrocyte invasion pathway of the malaria parasite Plasmodium falciparum. Cell 2005, I22:I83-193.

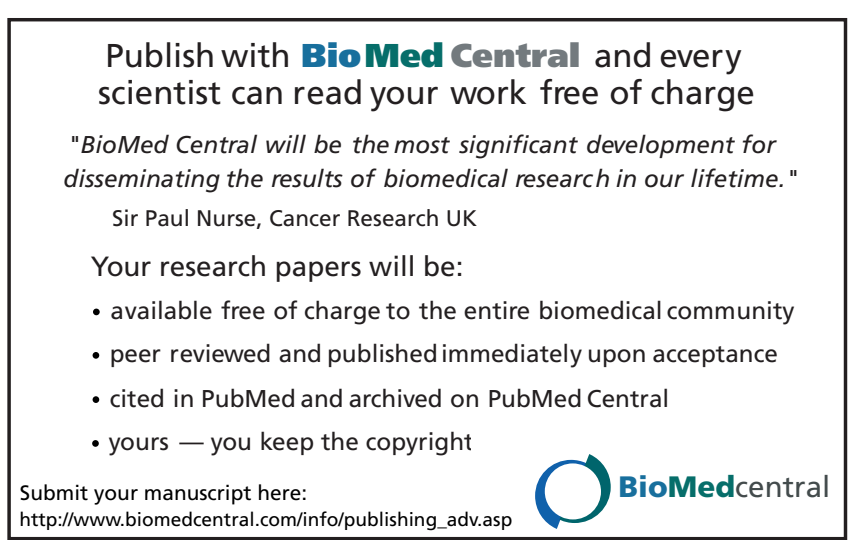

